\title{
Descentralização da atenção em HIV-Aids para a atenção básica: tensões e potencialidades
}

I ${ }^{1}$ Gustavo Zambenedetti, ${ }^{2}$ Rosane Azevedo Neves da Silva |

Resumo: Neste artigo, buscamos identificar e discutir as tensões que permeiam o processo de descentralização do diagnóstico para HIV e acompanhamento das pessoas vivendo com HIV-Aids para a atenção básica. Foi realizada uma pesquisa de base qualitativa, sob o viés analítico institucional, em Porto Alegre-RS. A análise considerou o recorte de dados referente aos grupos focais com equipes de uma unidade básica de saúde, entrevista com o coordenador municipal da política de DST-Aids, com profissional de matriciamento das ações de descentralização em HIV-Aids e com conselheiro local de saúde. Foram identificados problemas que tensionam o processo: equipes incompletas e rotatividade de profissionais; desconfiança em relação ao teste rápido; percepção de sobrecarga de trabalho; aspectos concernentes ao aconselhamento e comunicação diagnóstica. Entre os aspectos que tensionam favoravelmente para a efetivação do processo foram identificados: sensibilidade em relação aos dados epidemiológicos; perspectiva de trabalho segundo princípios do SUS e da saúde da família; capacitação e apoio matricial. Concluímos que o processo de descentralização envolve uma mobilização subjetiva do trabalhador e sua efetivação tem maiores condições de ocorrer sob a perspectiva de corresponsabilidade em vez de transferência de responsabilidade. A análise realizada pode auxiliar gestores e trabalhadores envolvidos em processos semelhantes.

> Palavras-chave: atenção primária à saúde; descentralização; HIV; assistência integral à saúde; análise institucional.

\author{
1 Departamento de Psicologia, \\ Universidade Estadual do \\ Centro-Oeste. Irati-PR, Brasil \\ (gugazam@yahoo.com.br). \\ 2 Instituto de Psicologia, \\ Universidade Federal do Rio \\ Grande do Sul. Porto Alegre-RS, \\ Brasil (rosane.neves@ufrgs.br).
}

Recebido em: 02/07/2015 Aprovado em: 05/02/2016 


\section{Introdução}

O município de Porto Alegre-RS tem sido destaque, na última década, por liderar o ranking de incidência de Aids entre as capitais brasileiras, com uma taxa de incidência de 93,7 casos/100 mil habitantes (BRASIL, 2013a), chegando a mais de 200 casos/100 mil habitantes em algumas regiôes de maior vulnerabilidade da cidade (STELLA; QUALISONE; MOISYN, 2011). Esses dados contrastam com a taxa de incidência de Aids, no Brasil, que foi de 20,2 casos /100 mil habitantes em 2013 (BRASIL, 2013a). O município também registra taxas elevadas de transmissão vertical e de mortalidade por Aids, estando esta última associada ao diagnóstico tardio - ou seja, quando o sistema imunológico já se encontra debilitado em decorrência da ação do HIV no organismo. Estudo realizado por Granjeiro et al. (2011) constatou que o risco de morte nos 12 primeiros meses após o diagnóstico está diretamente associado ao diagnóstico tardio e consequente início tardio do tratamento. Os autores afirmam que o acesso ao diagnóstico e tratamento no tempo considerado adequado poderia reduzir em até $50 \%$ as taxas brasileiras de mortalidade por Aids.

Nesse cenário, novas propostas assistenciais passam a surgir em nível local, conectadas a diretrizes políticas do Ministério da Saúde. Dentre essas ações, está a proposta de descentralização do acesso ao diagnóstico para a atenção básica, através da oferta de teste rápido para HIV e sífilis e aconselhamento nas unidades básicas de saúde (UBS). Em nível nacional, essas ações passaram a ser preconizadas através da Portaria no 77, de 12 de janeiro de 2012 (BRASIL, 2012), que dispõe sobre a realização de testes rápidos na atenção básica para a detecção de HIV e sífilis, assim como testes rápidos para outros agravos no âmbito da atenção pré-natal para gestantes e suas parcerias sexuais. A introdução dos testes rápidos está concebida de forma gradual, considerando-se a necessidade de treinamento dos profissionais e preparação do serviço para o acolhimento, aconselhamento, execução do teste, tratamento e encaminhamentos (BRASIL, 2013b). Manuais do Ministério da Saúde já indicavam a interseção entre HIV-Aids e atenção básica em ações preventivas, mobilização comunitária, aconselhamento e cuidados gerais da saúde de pessoas vivendo com HIV-Aids (PVHA) (BRASIL, 2006; 2005; 2003). A novidade consiste na inserção da oferta do diagnóstico nas UBS e na possibilidade de acompanhamento das PVHA, de modo corresponsável com 
os serviços especializados, expressando a passagem de um modelo centralizado para um modelo matriciado (BRASIL, 2014a). Essas experiências, no entanto, demonstram desenhos bastante singulares e diversos, como pode ser percebido nos relatos em torno de quatro experiências de descentralização em municípios brasileiros (BRASIL, 2014b).

$\mathrm{O}$ advento do teste rápido para HIV é considerado um dos aspectos que possibilitaram a inserção do diagnóstico na atenção básica. Sua oferta é estabelecida no SUS pela Portaria no 151, de 14 de outubro de 2009 (BRASIL, 2009), reconfigurando o diagnóstico para o HIV, visto reduzir o tempo necessário para o resultado a aproximadamente 30 minutos, enquanto o método tradicional levava em torno de 15 dias. Além disso, o teste rápido não demanda processamento laboratorial como o teste tradicional. Outro aspecto que pesa favoravelmente à descentralização é a capilarização da rede básica, em decorrência de sua forte expansão no Brasil nas últimas duas décadas.

Por outro lado, também são apontadas fragilidades da atenção básica que poderiam comprometer esse processo. Em entrevista concedida em 2014, o então secretário de saúde do município de São Paulo ponderava que a atenção básica apresenta uma série de problemas e que precisava ser mais bem estruturada para suportar a inserção de novas ações no campo da Aids. Nessa entrevista, também foi exposta a preocupação de alguns movimentos sociais que questionavam as condições da atenção básica para realizar uma atenção qualificada nessa área (BONANO, 2014). Desse modo, evidencia-se uma controvérsia em torno do processo de descentralização, visto com reserva por alguns setores, principalmente o movimento social relacionado à Aids. Considerando-se que as diretrizes acerca da descentralização da atenção em HIV-Aids são ainda recentes, há poucos estudos acerca desse tema, o que justifica o direcionamento deste artigo.

Compreendemos que a implantação de uma nova política não ocorre mecanicamente, mas mobiliza desejos, recursos e significados entre os participantes do processo, os quais podem tanto facilitar quanto dificultar a sua implementação.

Dentro desse contexto, buscamos analisar as tensões emergentes em um processo de descentralização do diagnóstico para HIV e sífilis e acompanhamento das PVHA para a atenção básica em saúde, no município de Porto Alegre-RS. 


\section{Contexto da pesquisa}

Em 2011, a Coordenação Municipal de DST-Aids de Porto Alegre adotou a diretriz de descentralização do diagnóstico de HIV e sífilis, que tem entre suas estratégias a inserção do teste rápido, do aconselhamento e do acompanhamento de PVHA dentro das UBS. Essa estratégia representa uma ruptura em relação às diretrizes políticas até então implementadas no município, consideradas centralizadoras - ou seja, com foco nos serviços especializados. O processo de descentralização teve início com um projeto-piloto, que abrangeu uma das oito gerências distritais do município, considerada com a maior taxa de incidência de Aids, superior a 200/100.000 habitantes:

Durante os meses de agosto e setembro de 2011, 77 profissionais (médicos e enfermeiros) das 22 unidades da Gerência Partenon / Lomba do Pinheiro foram capacitados para a implantação do aconselhamento, teste rápido e assistência aos portadores assintomáticos. (CGRAPS, s/p, 2011). ${ }^{1}$

O projeto-piloto foi desenvolvido em parceria entre a Secretaria da Saúde de Porto Alegre e órgãos da Secretaria Estadual de Saúde, como o Serviço de Atenção Terapêutica (SAT) e o Centro de Testagem e Aconselhamento (CTA) vinculados ao Hospital Sanatório Partenon.

A intenção desse projeto-piloto era fornecer subsídios para a ampliação do processo de descentralização a todo o município. Winkler et al. (2012) informam a publicação da Portaria no 289 , de 13 de março de 2012, que institui a realização de teste rápido para detecção do HIV e da sífilis no âmbito da atenção pré-natal para gestantes e suas parcerias sexuais, alavancando o processo de descentralização no município.

\section{Método}

Este artigo utiliza dados de uma pesquisa mais abrangente, intitulada "Processos de estigmatização e produção de territórios de inclusão/exclusão: a atenção em HIV-Aids na Estratégia Saúde da Família-ESF", vinculada à tese de doutorado defendida e orientada respectivamente pelos primeiro e segundo autores deste artigo. A pesquisa realizada teve abordagem qualitativa, sob o viés analítico institucional, utilizando-se das contribuições de autores como Baremblitt (1996), Lourau (1993; 2004), Foucault (1979). Essa abordagem permite o acompanhamento e a análise de processos de transformação, destacando os 
movimentos instituintes que tensionam a mudança e a inovação, assim como os aspectos instituídos, relacionados à cristalização, burocratização e aos pontos de estagnação. Rocha e Aguiar (2003) afirmam também que essa perspectiva analítica constitui-se como "ação desnaturalizadora", colocando em análise os efeitos das práticas no cotidiano do trabalho em saúde.

Para a análise, utilizamos as transcrições dos grupos focais realizados com três equipes de ESF de uma mesma unidade de saúde - foi realizado um grupo focal com médicos e enfermeiros, um com os Agentes Comunitários de Saúde (ACS); um com os técnicos de enfermagem e dois reunindo toda a equipe para restituição ${ }^{2}$ dos dados da pesquisa. Foram também utilizadas as transcrições das entrevistas com o gestor da política municipal de DST-Aids; com o profissional responsável pelo matriciamento das ações de descentralização para esta UBS; e com um representante do Conselho Local de Saúde (CLS). A UBS selecionada foi considerada a que realizou o maior número de testes rápidos, segundo levantamento realizado pela gestão municipal seis meses após o início do projeto, levando essa equipe a ser considerada aderente ao processo de descentralização. As transcriçõos das entrevistas com os usuários que realizaram o teste rápido na UBS, em um determinado corte temporal, foram analisadas em outro artigo (ZAMBENEDETTI, SILVA, 2015), visto que produziram outros focos analíticos.

Os dados da pesquisa foram produzidos entre dezembro de 2012 e julho de 2013. O projeto foi aprovado pelos Comitês de Ética em Pesquisa do Instituto de Psicologia da Universidade Federal do Rio Grande do Sul e da Secretaria Municipal de Saúde de Porto Alegre. A participação na pesquisa ocorreu mediante anuência através do Termo de Consentimento Livre e Esclarecido (TCLE).

A análise realizada circunscreve um fenômeno que permanece em andamento, sendo nossa proposta acompanhar um processo em constante transformação e não apenas constatar um estado de coisas. Nesse sentido, abrimos a apresentação dos resultados com uma contextualização da proposta de descentralização. A seguir, constituímos uma primeira linha analítica, que destaca receios, problemas ou desafios a serem superados, e uma segunda linha, que destaca as potencialidades instituintes. Essas linhas constituem uma trama e tensionam umas às outras. Com vistas à não identificação dos participantes, os trechos de falas expostos na análise serão identificados pelo lugar ocupado (gestor, trabalhador ou CLS), serviço (ESF ou matriciamento) seguido de um número, no caso das categorias onde houve mais de um participante. 


\section{Reconfigurando as atribuições da atenção básica e da atenção especializada}

A proposta de descentralização envolvia as seguintes mudanças:

- inserção de teste rápido e aconselhamento nas UBS com e sem ESF;

- solicitação de exames de CD4 e CV pela UBS, assim como realização da primeira consulta médica pós-diagnóstico;

- acompanhamento das PVHA assintomáticas nas UBS;

- encaminhamento das PVHA assintomáticas atendidas nos serviços especializados para serviços de Atenção Básica;

- atribuição da função de matriciamento aos serviços especializados, como SAE e CTA;

$\mathrm{Na}$ percepção da gestão municipal em DST-Aids, a grande incidência e prevalência de casos de Aids no município de Porto Alegre exigem uma reconfiguração da rede de saúde, com maior preparo para atendimento nas UBS.

Com a questão do tratamento, as pessoas vivem mais. Em elas vivendo mais, elas precisam mais cuidados. Em elas precisando de mais cuidados, elas precisam de mais consultas. (...) Em média, são 100 novas PVHA/mês. Isso em todos os centros de saúde, contando os 4 CTAS, todos os diagnósticos feitos em Porto Alegre. É muito alto. Então, essas pessoas necessitam de um serviço de saúde e os serviços especializados não dão conta dessa demanda. Mesmo que a gente consiga aumentar a sua capacidade, eles não conseguem dar conta. (Gestão)

A sobrecarga de serviços especializados também foi relatada em outras experiências, como no município do Rio de Janeiro (BRASIL, 2014b). A gestão também considera que, historicamente, a atenção básica mostrou-se impermeável a questôes relacionadas às DST-Aids, sendo a inserção do diagnóstico uma estratégia para o debate sobre a atenção em HIV-Aids nesse nível de atenção.

Esse processo envolveu uma reconfiguração do que é considerado concernente à Atenção Básica ou especializada. Na perspectiva da gestão municipal da política em HIV-Aids, considera-se que o acompanhamento padrão da PVHA assintomática consiste no exame médico-clínico periódico e solicitação de exames para acompanhamento da carga viral e situação imunológica, o que poderia ser realizado na atenção básica. Além disso, considera-se que quaisquer manifestações 
de problemas de saúde não correlacionados ao HIV-Aids poderiam ser tratadas na atenção básica.

Por outro lado, a atenção especializada seria indicada no momento em que se fizesse necessária a utilização das medicações antirretrovirais, quando surgissem intercorrências da Aids, em casos de coinfecção (HIV e Hepatite B, HIV e tuberculose) ou quando houvesse problemas relacionados à adesão ao tratamento (BRASIL, 2014a).

Um dos aspectos que tornaram essa situação mais complexa foi a mudança introduzida nas recomendaçôes de terapia antirretroviral para adultos vivendo com HIV/Aids em 2012, com a alteração dos critérios para o início do uso de medicação antirretroviral (ARV). Essa medida teve como impacto a ampliação da indicação do uso de ARV para pacientes assintomáticos. Em 2013, passou a ser preconizado o "início imediato da TARV [Terapia antirretroviral], na perspectiva da redução da transmissibilidade do HIV, considerando a motivação da PVHA" (BRASIL, 2013c, p. 64). Segundo os participantes da pesquisa, a partir dos novos critérios de uso de medicação, a maioria dos usuários foi encaminhada para serviços especializados. No entanto, apesar do encaminhamento, a área de referência continua sendo o território de atuação da ESF. Portanto, seria esperado que a ESF continuasse informada sobre o acompanhamento realizado à PVHA, em uma perspectiva de corresponsabilização (BRASIL, 2014a, 2014b).

A descentralização promove uma mudança na relação entre as ações em HIVAids e os níveis de atenção do SUS, evidenciando que a atribuição de ações a um nível do sistema é uma convenção, atravessada por condições históricas e políticas: históricas em decorrência de estarem situadas no tempo e políticas por envolverem disputas entre posições, atores, recursos e concepções. A implantação de uma política é permeada por movimentos contraditórios, que oscilam da aderência ao rechaço, e que envolvem, muitas vezes, a recusa das propostas de mudança, como indicado no relato:

Assim como tu tens equipes extremamente abertas a incorporar novas práticas em saúde, têm equipes muito resistentes. (Gestão)

Consideraremos, a seguir, duas linhas de análise. Na primeira, são destacados os aspectos associados a problemas e desafios. $\mathrm{Na}$ segunda, aqueles aspectos que potencializam o desenvolvimento das ações de descentralização. 


\section{Problemas e desafios que tensionam o processo}

\section{Confiabilidade do teste}

Em relação ao teste rápido, foi relatada a existência de uma desconfiança quanto à sua efetividade, advinda principalmente da categoria médica, conforme relato a seguir:

Está tendo muita resistência dos médicos, porque eles não estão acreditando... tem essa coisa de "fé" no teste rápido, acho isso tão engraçado, assim [tom irônico]. Tem que acreditar no teste rápido, não é nada científico, é tudo fé. Aí a gente vai lá fazer um convencimento na reunião de equipe e tal. (Matriciamento)

A não confiabilidade no teste também fazia com que alguns médicos, diante de resultado reagente para HIV no teste rápido, solicitassem o teste laboratorial, considerando que apenas este poderia confirmar o diagnóstico - diferentemente do que concebe a Portaria no 151/2009 (BRASIL, 2009), que dispõe sobre o fluxo de diagnóstico. Isso repercutia na necessidade de deslocamento dos usuários e postergação do início de seu tratamento.

\section{Sobrecarga de trabalho}

Outro receio apontado entre as equipes da gerência relaciona-se à sobrecarga de trabalho:

Eu lembro que no início tinha muito essa questão do sofrimento da equipe, onde é que a gente vai achar um horário nas agendas, do que vamos abrir mão, o quanto isso vai nos sobrecarregar. (ESF, Prof. 5).

A sobrecarga de trabalho não diz respeito a uma quantidade de horas a mais trabalhadas, mas à responsabilidade por mais uma área de açôes, com a exigência de uma reconfiguração do processo de trabalho.

Agora, as enfermeiras que começaram, por exemplo, ali, as minhas unidades, a grande resistência delas é que elas achavam que ia ser muito trabalho a mais. Até porque se tu vê a quantidade de coisinha que tu tem que preencher e prestar atenção nisso, e isso, isso leva aquilo e aquilo lá... é uma parafernália de coisas. (Matriciamento)

Dessa forma, a equipe precisa rever seu processo de trabalho, o que demanda pensar, refletir e discutir. Trata-se de se deslocar do cotidiano instituído para planejar novas ações:

Mas não é uma coisa do domínio, então é uma coisa que me cansa, porque eu tenho que pensar muito. Eu imagino que, para quem nunca trabalhou com Aids, fazer um diagnóstico é difícil. (Matriciamento) 
Ainda dentro desse contexto, identificamos um movimento de incorporação e estabilização das ações dentro das unidades:

E agora, no final do ano, elas estavam avaliando assim: "está completamente dentro da rotina do posto", "não tem nenhuma diferença, a gente nem nota que tem isso como mais uma demanda”. É algo absolutamente assimilado. (Matriciamento)

Através dos trechos de falas apresentados, é possível identificar o embate entre forças instituintes e aspectos instituídos. Os receios e a sensação inicial de sobrecarga atuam sobre os trabalhadores no sentido da imobilidade, de evitar a mudança, enquanto as forças instituintes os mobilizam e os impelem ao processo de mudanças, culminando no processo de institucionalização - ou seja, quando se produz uma sensação de estabilidade, de naturalização, como denota a expressão "a gente nem nota que tem isso como mais uma demanda". A institucionalização de um processo, em si, não pode ser associada a algo negativo ou ruim. Porém, é necessário que seus efeitos sejam constantemente colocados em análise, buscando-se evitar processos de burocratização caracterizados como aqueles onde o pensar e o agir tornam-se dissociados (LOURAU, 2004).

\section{Equipes incompletas e rotatividade}

Os profissionais das equipes de ESF relataram a existência de equipes incompletas em UBS da gerência, restringindo o acesso à população.

A rotatividade de profissionais também foi percebida como um aspecto que dificulta tanto a implantação quanto a continuidade da ação. Entre o momento de realização do grupo focal com as técnicas de enfermagem (janeiro) e a restituição da pesquisa (realizada em julho), apenas uma das cinco técnicas de enfermagem participantes do grupo focal permanecia na UBS. Do mesmo modo, dos três enfermeiros, apenas um permanecia na unidade. A rotatividade é atribuída à substituição do órgão que realiza a contratação dos profissionais para atuação na ESF e em decorrência da solicitação de remoção de profissionais para outra(s) unidade(s), pois, inicialmente, assumem onde existe a vaga disponível e, posteriormente, solicitam remoção para outra UBS.

Esses problemas mencionados dificultam a concretização de formação de vínculo, referência e responsabilização do serviço sobre o território de atuação, consideradas características importantes da atenção básica (ANDRADE; BUENO; BEZERRA, 2009). Nesse sentido, questôes relacionadas à estruturação 
da equipe podem dificultar a operacionalização de princípios concernentes ao trabalho sob a ótica da saúde da família. Esse aspecto ficou ainda mais evidente durante levantamento realizado junto à coordenação da UBS acerca dos diagnósticos de HIV realizados desde o início da descentralização. Foi possível observar que, em alguns casos onde o diagnóstico foi realizado por um profissional que não estava mais na UBS, a equipe não estava familiarizada com o histórico dos diagnósticos, desconhecendo os encaminhamentos realizados e a situação atual de tratamento.

\section{Expectativa de inexistência ou de elevada procura pelo teste}

A expectativa das equipes frente à descentralização oscilava entre a inexistência de procura pelo teste e a elevada procura pelo mesmo. A expectativa de pouca procura ocorria sob o argumento de que as pessoas poderiam se sentir intimidadas em decorrência do estigma associado à Aids e pela associação com a sexualidade. No entanto, esse receio foi dissipado pela equipe após o início das ações, na medida em que se percebeu a existência de procura pelo teste: em média, de 6 a 8 agendamentos por semana. Isso não significa que o estigma e a preocupação com a exposição da sexualidade não estivessem presentes, mas essas preocupaçôes se expressam de outras maneiras, como no desejo de que o acesso à unidade de saúde não fosse percebido pela comunidade e na preocupação com a privacidade e o sigilo das informaçóes referentes aos usuários. Abdala e Nichiata (2008) e Almeida e Lambronici (2007) destacam que o manejo do sigilo e privacidade no acesso ao cuidado em HIV-Aids deve ser discutido pelas equipes de atenção básica, pois a não garantia desses aspectos pode representar barreiras ao acesso e continuidade do tratamento. Nessa perspectiva, consideramos que o estigma associado ao HIV não deve ser um empecilho para o processo de descentralização, mas sim um aspecto a ser abordado durante esse processo, garantindo a sua compreensão e manejo.

Foi relatada a heterogeneidade do público que procura o teste entre as unidades da gerência, oscilando entre as unidades que centraram a realização do teste entre as gestantes e suas parcerias sexuais e aquelas que ampliaram o acesso para o público em geral, como o caso da unidade de saúde participante da pesquisa. A delimitação do público gestante por parte de algumas equipes revela dois aspectos: por um lado, um modo de contenção da demanda pelo teste 
rápido; por outro, a dificuldade em lidar com a abordagem desse tema com o

público em geral, principalmente em decorrência da sexualidade e da moralidade associadas à Aids.

Elas achavam mais fácil explicar para o paciente que ia fazer o teste se fosse gestante. Porque gestante já sabe que vai fazer. É diferente de tu ir num grupo de diabético e sugerir que eles façam o teste: por que um diabético vai fazer um teste de HIV, entende? (Matriciamento)

Nesse sentido, a oferta do teste está atrelada à explicitação de algo aparentemente óbvio, mas que nem sempre é apontado por ser considerado da ordem da intimidade e privacidade: a vida sexual. Isso porque a via sexual é a principal forma de infecção pelo HIV (BRASIL, 2013a) e porque, em torno da sexualidade, existe uma complexa construção social e simbólica, a qual deve ser considerada nas ações de aconselhamento e testagem para HIV.

\section{Aconselhamento / comunicação do diagnóstico}

Outro receio presente entre os profissionais dizia respeito à comunicação do diagnóstico de HIV reagente: "muito pela pressão do diagnóstico: nós vamos dar diagnóstico de HIV para alguém?” (ESF, Prof. 2). Outros profissionais, como os técnicos de enfermagem, também percebiam esse receio. Porém, mencionam que isso ocorria nas outras unidades, e não na unidade participante da pesquisa.

O pessoal [das outras UBS] não quer fazer porque acha que não tem condições de dar um diagnóstico, porque realmente é uma coisa pesada, né? Para dizer para a pessoa, né? É complicado mesmo, realmente. Eu acho que assusta um pouco. (ESF, Téc. Enf. 1).

Uma profissional da equipe de ESF relatou que isso ainda a preocupava:

Eu ainda tenho uma angústia de dar o diagnóstico positivo. Porque eu me coloco muito no lugar da pessoa. Dos testes que eu fiz, um que deu [positivo] e daí até chamei a [outra enfermeira] para me acompanhar. Eu ainda tenho essa angústia. Porque durante o treinamento que a gente teve, nenhum dos pacientes que a gente fez deu positivo. Então eu não sabia muito bem como abordar. (...) Eu já tava vendo, já fui preparando, fiz já o segundo teste, deu positivo, né, confirmou, daí na hora de abordar assim... fiquei assim meio... isso me emocionou. (ESF, Prof. 3)

Apesar da comunicação do diagnóstico reagente para HIV ser fonte de mobilização, tradicionalmente, os manuais sobre aconselhamento (BRASIL, 1999) ressaltam que é tão desafiador comunicar um resultado reagente quanto um não reagente para HIV. Isso porque, no caso do resultado não reagente para 
HIV, o desafio é criar estratégias de sensibilização para a prevenção, visando à manutenção da soronegatividade para o HIV.

Também foram relatados aspectos em relação ao aconselhamento: "Ainda fico meio enrolada na hora de aconselhar, fazer o teste é mais tranquilo. Às vezes na hora de aconselhar saem as perguntas mais inusitadas" (ESF, Prof. 3). $\mathrm{O}$ aconselhamento exige a habilidade para lidar com uma ampla gama de dúvidas e perguntas, relacionadas ao âmbito da sexualidade humana em suas múltiplas formas de expressão, exigindo habilidades para colocar em análise preconceitos e pré-julgamentos, assim como para desenvolver uma relação de alteridade. Enquanto o teste tem como finalidade o diagnóstico, abrindo a possibilidade do encaminhamento para tratamento e prevenção da transmissão vertical (mãe-bebê), o aconselhamento "possibilita a identificação e discussão dos motivos e problemas que demandaram o teste, permitindo ao sujeito refletir e compreender os modos pelos quais pode evitar a infecção pelo HIV e os desafios pessoais e relacionais implicados no esforço de adoção das medidas de proteção" (MORENO, 2013, p. 166).

Foi indicado, por parte do profissional responsável pelo matriciamento, o receio de que o papel do aconselhamento na atenção básica seja relegado a um segundo plano em relação à realização do teste. Nesse sentido, chamamos a atenção para o risco de tecnicização do diagnóstico, concebido como um processo no qual a ênfase da ação recai sobre a oferta e realização do teste em si, desvinculado da abordagem preventiva, da avaliação de riscos e do apoio emocional que caracterizam a prática do aconselhamento. É importante destacar que o aconselhamento pode promover a sensibilização para a prevenção e para a adesão ao tratamento, a redução do impacto do diagnóstico, entre outros aspectos (MORENO, 2013). O aconselhamento expressa, ainda, uma dimensão ética e política, relacionada à escuta do sujeito e comprometimento com a construção conjunta de possibilidades de resolução dos problemas apresentados.

Foi observado, ainda, que o aconselhamento não está incorporado na formação profissional de médicos e enfermeiros, sendo o processo de capacitação e matriciamento de fundamental importância para a sua conformação.

\section{As "oportunidades perdidas" nas rotinas do trabalho}

Durante um dos encontros de restituição, foram relatadas situações nas quais as ações de testagem deixam de ser ofertadas, despertando uma reflexão sobre 
as chamadas "oportunidades perdidas". Segundo Paula e Santos (2013), as "oportunidades perdidas" designam as situações que seriam consideradas privilegiadas para a abordagem preventiva das DST, como a solicitação do exame de gravidez ou a realização do Papanicolau, mas que acabam sendo "perdidas" em função da não realização da abordagem. Durante um dos encontros de restituição da pesquisa, uma técnica de enfermagem relatou que, muitas vezes, meninas procuram a unidade de saúde solicitando a realização de exame para gravidez e os profissionais não se lembram de ofertar o teste para HIV e outras DST, perdendo um momento que seria considerado importante.

Essas situações revelam a criação de rotinas e pontos de cristalização no cotidiano de trabalho da(s) equipe(s) de ESF, onde nem sempre ocorre a integração entre as várias dimensões que podem envolver uma ação em saúde. Por outro lado, o reconhecimento dessas situaçóes pela própria equipe indica a sua potência autoanalítica e de autogestão. Inspirados em Baremblitt (1996), podemos considerar que a autoanálise diz respeito ao movimento de ampliação da compreensão da equipe acerca de determinado tema, valorizando seus saberes, enquanto a autogestão diz respeito aos modos de (re) organização da equipe a partir da compreensão que ela passa a ter de si mesma.

Os movimentos de autoanálise e autogestão podem conferir às equipes características de plasticidade, aspecto observado na equipe da UBS participante da pesquisa. A "plasticidade" diz respeito à habilidade da equipe em analisar constantemente seu processo de trabalho e reorganizá-lo, conforme as novas demandas emergentes e as suas condições de efetivação. Trata-se de uma disposição para mudanças, para o desenvolvimento de novos projetos e também de uma percepção relacionada à aprendizagem com o próprio trabalho. Podemos pensar a plasticidade como uma força instituinte que tensiona a burocracia, a fragmentação e as rotinas paralisantes.

\section{Aspectos que potencializam o processo de descentralização Sensibilidade em relação aos dados epidemiológicos}

Para a equipe de ESF, a proposta de descentralização em HIV-Aids foi apresentada em reuniōes realizadas junto à Gerência Distrital de Saúde, coincidindo com o momento em que a equipe já discutia a descentralização em relação à tuberculose. Em decorrência de uma elevada associação entre tuberculose e Aids (coinfecção), a equipe considerou coerente aderir ao processo. 
Um dos panos de fundo de sensibilização da equipe era o conhecimento da alta incidência e prevalência de Aids na região de abrangência da unidade de saúde, expresso por diversos membros da equipe, contrastando com o que foi encontrado em pesquisa realizada em 2009 com uma equipe de ESF da mesma gerência distrital. No estudo, foi constatado que os profissionais não tinham conhecimento sobre os dados epidemiológicos relacionados à Aids em sua região de abrangência e no município de Porto Alegre-RS, que, naquela ocasião, já liderava o ranking de municípios com maior incidência de Aids (ZAMBENEDETTI; BOTH, 2012). Evidencia-se, portanto, a importância da apropriação dos dados epidemiológicos por parte das equipes de saúde e sua utilização para o planejamento de açôes.

\section{Lógica de trabalho sob os princípios do SUS e da saúde da família}

Os profissionais justificaram também a inserção de ações em HIV-Aids com base nos princípios que constituem a saúde da família. No grupo focal com médicos e enfermeiros das equipes de ESF, foi relatada a compreensão da atenção básica como porta de entrada do sistema, sob os princípios de integralidade e de longitudinalidade do cuidado, que corresponde à necessidade de continuidade do acompanhamento mesmo quando o usuário é encaminhado a outro serviço. A percepção de ampliação de acesso à saúde também foi mencionada por trabalhadores e gestor como um aspecto que os mobiliza em direção ao processo de descentralização. Deve-se considerar, ainda, que todos os médicos e parte dos enfermeiros da UBS haviam realizado formação em programas de residência em saúde da família e atenção básica, o que possivelmente contribuiu para a construção de um trabalho pautado por essa lógica. Além disso, a UBS era campo de formação para um programa de residência médica e multiprofissional em atenção básica.

Essa percepção contrasta com aquela de profissionais de algumas UBS do município, que compreendem que o diagnóstico para HIV e o acompanhamento devem continuar sendo responsabilidade dos serviços especializados. Tanto gestores como trabalhadores da equipe de ESF indicaram que o processo de descentralização ocorre com maior dificuldade nas UBS sem equipe de ESF, conhecidas como "UBS tradicionais", que tendem a resistir a qualquer tipo de mudança. 
A integração das ações de aconselhamento e testagem também foi indicada como uma potencialidade, visto que antes da implantação do teste rápido, as UBS apenas encaminhavam os usuários para laboratórios conveniados com a Secretaria Municipal de Saúde. Os resultados não reagentes eram entregues diretamente aos usuários, enquanto os resultados reagentes para HIV não eram entregues, sendo recomendada ao usuário a procura por um CTA para repetição do exame. Ocorria, assim, uma desvinculação entre o pedido do teste (feito na unidade de saúde), sua realização (em um laboratório) e a busca pelo resultado (alguns dias depois, no laboratório), fragmentando a relação entre UBS, laboratório e CTA. Esse relato é consoante com o encontrado em Zambenedetti e Both (2012). Mattos (2003) afirma que a integralidade é um conceito polissêmico. Consideramos que um de seus sentidos ou dimensões foi contemplado no contexto analisado, o sentido de integração de ações em torno da atenção ao usuário.

\section{Participação da comunidade}

A participação da comunidade foi mediada pelo CLS, ativo na UBS participante da pesquisa. Um de seus conselheiros relatou ter participado de uma capacitação promovida pela coordenação municipal de DST-Aids com lideranças comunitárias, para que pudessem contribuir com o processo de descentralização. Após essa capacitação, esse representante do CLS e outros moradores locais auxiliaram na divulgação do teste na comunidade e na coleta de nomes para agendamento do teste. Também auxiliavam na distribuição de preservativos em pontos estratégicos da comunidade, como escolas, bares, boates, conforme relato: Aqui nos fundos tem um bar também! Bar do... mas não tem nada, de minimercado não tem nada! É só cachaça, trago e cocaína! Aí eu distribuo uma caixa [de preservativos], largo toda quarta-feira uma caixa. (CLS)

O CLS foi utilizado pela equipe como ferramenta de aproximação da UBS com a população, em decorrência do conhecimento do território e da capacidade de produzir mobilização. Sua atuação parece se confundir com o que seria esperado da atuação dos ACS. A equipe referiu sua importância principalmente no início do processo, pois, passados alguns meses do início das ações, elas foram incorporadas pela equipe, diluindo a função do representante do CSL. 


\section{Capacitação, matriciamento e mobilização subjetiva}

A equipe de matriciamento é composta por profissionais de diferentes formações (Psicologia, Serviço Social, Enfermagem e Ciências Sociais). A gerência distrital é composta por 22 equipes, divididas em eixos, para os quais foram designados profissionais da equipe de matriciamento. Em um dos eixos, um profissional ficou responsável por seis unidades, uma das quais é a unidade de saúde participante desta pesquisa; nos outros dois eixos, ficaram dois profissionais responsáveis por 8 unidades em cada eixo. Esses profissionais constituíam-se como referências para o apoio às equipes, em consonância com as caracterizações feitas por Campos e Domitti (2007).

Foi relatado que o matriciamento não ocorreu de modo idêntico nos três eixos, variando conforme as concepçôes presentes entre os profissionais: alguns entendem que a capacitação já deveria ser suficiente para a implantação das ações, enquanto outros compreendem a necessidade de acompanhamento contínuo das açôes. No eixo de responsabilidade da profissional entrevistada, o acompanhamento era feito mediante reunião mensal com os coordenadores das UBS, contatos telefônicos e por e-mail. As equipes de ESF mencionaram a importância do matriciamento para qualificação das ações, mas consideraram que seria importante que o matriciador pudesse também fazer reuniōes com toda a equipe das UBS e não apenas com um representante da unidade. Também mencionaram demandas relacionadas ao manejo clínico da Aids, as quais não eram supridas pelas formaçôes profissionais presentes no matriciamento, mais focadas no aconselhamento, teste rápido e articulação da rede. Os sentidos de apoio matricial operados estão em acordo com o proposto por Campos e Domitti (2007), que consideram que o matriciamento envolve a criação de uma lógica de compartilhamento e corresponsabilização, conforme pode ser percebido a seguir:

E aí em seguida foi feita a capacitação e a gente achava que ia se postergar o início. E de repente não, está vindo uma equipe que vai ajudar nos primeiros testes, vão ficar uma manhã aqui, e vamos fazer, né. (...) Mas depois dos primeiros testes, a equipe foi se organizando, e enfim, ficou tranquilo. (ESF, Prof. 5).

A presença de profissionais da equipe de matriciamento auxiliando a organizar as primeiras ações dentro da UBS foi considerada um aspecto que potencializou a descentralização, diminuindo os receios e facilitando o início das ações. Deste modo, pontua-se que a capacitação, isoladamente, tem um alcance limitado. 
Por outro lado, a conjunção entre o momento formativo e o acompanhamento contínuo realizado através do matriciamento potencializou a efetivação das ações.

É importante destacar que os municípios têm constituído experiências muito singulares na conformação do matriciamento. Em relato de experiência presente em Brasil (2014b), observa-se a proposta de conformação do matriciamento através da contratação de infectologistas para atuação nos Núcleos de Apoio a Saúde da Família (NASF), diferente da proposta operada em Porto Alegre-RS, onde o matriciamento é uma das ações dos profissionais do serviço de referência.

Deve-se destacar que tanto os processos formativos quanto o matriciamento interferem na mobilização subjetiva do trabalhador, aspecto fundamental para a efetivação dos processos de mudança. $\mathrm{O}$ conceito de mobilização subjetiva foi criado por Cristoph Dejours e diz respeito ao investimento que o trabalhador faz para (re) criar sua ação de trabalho, podendo transformar sensações de desconforto e sofrimento psíquico relacionados ao trabalho em situações prazerosas (MENDES; COSTA; BARROS, 2003). Esse processo é vivenciado de forma muito particular por cada trabalhador e se constitui como um contraponto às estratégias defensivas. Consideramos que esse conceito torna-se relevante por afirmar que o trabalhador não é um simples executor de tarefas, mas sempre um (re)criador de ações. Essa criação pode envolver a mobilização de angústia, diante da incerteza e insegurança, como expresso no trecho a seguir:

Porque a gerência não nos dizia assim "vai ter que ter um turno, dois turnos, a semana toda". No início, a gente pensava assim: "livre demanda", sabe, chegou na unidade vai fazer. E aí isso assim foi muito sofrido para a equipe toda. (ESF, Prof. 5)

Esse movimento de implantação de uma diretriz política é perpassado por relaçôes de poder, expressas no relato de um trabalhador:

O gestor diz: "vamos fazer!"; A gerência diz "vamos fazer, mas vamos ver como fazer"; E o trabalhador diz "vamos fazer, vamos ver como fazer e vamos com calma!".

(Matriciamento)

Essa afirmação explicita o modo como uma diretriz vai sendo recebida por profissionais que ocupam diferentes posições nas relações hierárquicas de gestão/ atenção, enunciando um movimento de reapropriação da diretriz política no curso de tais posições. Mendes, Costa e Barros (2003) afirmam que, apesar da mobilização subjetiva ser vivenciada individualmente, ela é influenciada por diversos aspectos sociais e institucionais: 
Tal mobilização depende da margem de liberdade oferecida ao trabalhador para ajustar suas necessidades pessoais às situações de trabalho. É necessário um espaço para discussão, participação, cooperação e solidariedade dos trabalhadores, especialmente uma crença nas mudanças e nas suas contribuições efetivas para as modificações das situações cotidianas do trabalho (p. 61).

Nesse sentido, a mobilização subjetiva não diz respeito isoladamente a uma característica interna ao sujeito, sendo modulada por relações coletivas no contexto social e de trabalho. Os momentos de formação, assim como o acompanhamento proporcionado pelo matriciamento, podem ser considerados espaços privilegiados para esse exercício de coletivização e corresponsabilização pelas ações.

\section{Considerações finais}

Através da pesquisa realizada foi possível caracterizar o processo de descentralização da atenção em HIV-Aids enquanto um fenômeno complexo e multifacetado, onde diversas forças estão presentes, tensionando as dificuldades e as potencialidades. Entre as dificuldades, destacamos: - Equipes incompletas e rotatividade dos profissionais da equipe; - Confiabilidade no teste; - Percepção de sobrecarga de trabalho; - Expectativas de inexistência de procura e/ou de elevada procura pelo teste; - Aconselhamento e comunicação do diagnóstico; Rotinas do processo de trabalho. Alguns desses aspectos dizem respeito ao modo de gestão e estruturação da ESF, ainda fragilizado, repercutindo sobre aspectos da atenção ao usuário. Por outro lado, entre as potencialidades, destacamos: - Sensibilidade em relação aos dados epidemiológicos; - Percepção acerca da ampliação do acesso; - Lógica de trabalho orientada pelos princípios do SUS e da saúde da família; - Capacitações e apoio matricial; - Participação da comunidade.

A discussão sobre a mobilização subjetiva do trabalhador traz à tona os vários aspectos envolvidos em um processo de descentralização, sendo que a concretização do mesmo envolve não apenas a vontade pessoal de um trabalhador, mas as condiçôes estruturais para que o processo seja desenvolvido, assim como mecanismos de sensibilização, acompanhamento e qualificação, designando ao mesmo um sentido de corresponsabilidade e compartilhamento em vez de simples transferência de responsabilidade. As capacitações em articulação com o apoio matricial mostraram-se como importantes estratégias para auxiliar na mobilização em direção à mudança. 
Esperamos que o conhecimento produzido neste artigo possa ser contrastado com outras produçôes e novas pesquisas na área, ampliando a compreensão acerca desse tema. Além disso, esperamos que a análise realizada possa subsidiar o planejamento de processos de descentralização das ações em HIV-Aids em outros municípios. ${ }^{3}$

\section{Referências}

ABDALA, F.T.M.; NICHIATA, L.Y. I. A abertura de privacidade e o sigilo das informações sobre o HIV/Aids das mulheres atendidas pelo Programa Saúde da Família no Município de São Paulo, Brasil. Revista Saúde e Sociedade, São Paulo, v. 17, n. 2, p. 140-152, 2008.

ALMEIDA, M.R.C.B.; LABRONICI, L. M. A trajetória silenciosa de pessoas portadoras do HIV contada pela história oral. Ciência \& Saúde Coletiva, Rio de Janeiro, v. 12, n. 1, p. 263-274, 2007.

ANDRADE, L.O.M.; BUENO, I.C.H.C.; BEZERRA, R.C. Atenção primária à saúde e Estratégia Saúde da Família. In.: CAMPOS, G.W.S. et al (Org.). Tratado de Saúde Coletiva. São Paulo: Hucitec; Rio de Janeiro: Fiocruz, 2009. p. 783-836.

BAREMBLITT, G. Compêndio de Análise Institucional e outras correntes - teoria e prática. Rio de Janeiro: Rosa dos Tempos, 1996.

BONANNO, L. SP não está preparada para atender HIV na atenção básica, diz secretário. Site UOL. 24/01/2014. Disponível em: http://noticias.uol.com.br/saude/ultimas-noticias/ redacao/2014/01/24/sp-nao-esta-preparada-para-atender-hiv-na-atencao-basica-dizsecretario.htm. Acesso em: 27 jan. 2014.

BRASIL. 5 passos para a implementação do manejo da infeç̧ão pelo HIV na Atenção Básicaguia para gestores. Brasília: Ministério da Saúde, 2014a.

. Cadernos de boas práticas em HIVIAids na Atenção Básica. Brasília: Ministério da Saúde, 2014b.

. Boletim Epidemiológico Aids - DST. Ano II, no 1. Brasília: Ministério da Saúde, 2013a.

. Guia orientador para a realização das capacitaçōes para executores e multiplicadores em Teste Rápido para HIV e Sífilis e Aconselhamento em DST/Aids na Atenção Básica para gestantes. Brasília: Ministério da Saúde, 2013b.

. Protocolo clínico e diretrizes terapêuticas para manejo da infecção pelo $H I V$ em adultos. Brasília: Ministério da Saúde, 2013c.

Portaria no 77 , de 12 de janeiro de 2012. Dispõe sobre a realização de testes rápidos, na Atenção Básica, para a detecção de HIV e sífilis, assim como testes rápidos para outros agravos, no âmbito da atenção pré-natal para gestantes e suas parcerias sexuais. 2012. 

- Portaria SVS/MS no 151, de 14 de outubro de 2009. Brasília: Ministério da Saúde, 2009. Disponível em: <http://bvsms.saude.gov.br/bvs/saudelegis/svs/2009/ prt0151_14_10_2009.html>. Acesso em: jan. 2014.

. HIVIAids, hepatites e outras DST / Cadernos de Atenção Básica, no 18 (Série A. Normas e Manuais Técnicos). Brasília: Ministério da Saúde, 2006.

Oficina de Aconselhamento em DST/HIVIAIDS para a Atenção Básica. Brasília: Ministério da Saúde, 2005.

. Aconselhamento em DST/HIVIAids para a Atenção Básica. Brasília: Ministério da Saúde, 2003.

. Aconselhamento em DST, HIV e AIDS: diretrizes e procedimentos básicos. Brasília: Ministério da Saúde, 1999.

CAMPOS, G.W.S; DOMITTI, A.C. Apoio matricial e equipe de referência: uma metodologia para gestão do trabalho interdisciplinar em saúde. Cad. Saúde Pública, Rio de Janeiro, v. 23, n. 2, p. 399-407, 2007.

FOUCAULT, M. Microfísica do Poder. Rio de Janeiro: Ed. Graal, 1979.

LOURAU, R. René Lourau: analista institucional em tempo integral. São Paulo: Hucitec, 2004. UERJ, 1993.

Análise Institucional e práticas de pesquisa - René Lourau na UERJ. Rio de Janeiro:

MATTOS, R. A. Os sentidos da integralidade: algumas reflexões acerca de valores que merecem ser defendidos. In: PINHEIRO, R.; MATTOS, R.A. (Org.). Os sentidos da integralidade. Rio de Janeiro: IMS-UERJ / ABRASCO, 2003. p. 39-64.

MENDES, A. M.; COSTA, V. P. ; BARROS, P.C.R. Estratégias de enfrentamento do sofrimento no trabalho bancário. Estudos e Pesquisas em Psicologia, Rio de Janeiro, v. 3, n. 1, p. 59-72, 2003.

MORENO, D.M.F.C. Aconselhamento para revelação do diagnóstico de infecção pelo HIV. In: PAIVA, V.; CALAZANS,G.; SEGURADO, A. (Org.). Vulnerabilidade e direitos humanos: Promoção e Prevenção da saúde. Livro II. Curitiba: Juruá, 2013. p. 165 - 188.

PAULA, I.A.; SANTOS, N.J.S. A prevenção às DST/Aids nos serviços de Atenção Básica no estado de São Paulo, 2012. In: PAIVA, V.; CALAZANS, G.; SEGURADO, A. (Org.). Vulnerabilidade e direitos humanos - prevenção e promoção da saúde. Livro II. Curitiba-PR: Ed. Juruá, 2012. p. 219 - 240.

ROCHA, M.L.; AGUIAR, K.F. Pesquisa-intervenção e a produção de novas análises. Psicologia: Ciência e Profissão, Brasília, v. 23, n. 4, p. 64-73, 2003.

STELLA, I.M.; QUALISONI, C.M.D.; MOISYN, D.C. Aids em Porto Alegre. Boletim Epidemiológico (Secretaria Municipal de Saúde de Porto Alegre), ano XIII, no 45, p. 2-3, 2011. 
WINKLER, G.B. et al. Teste rápido para o HIV e a sífilis, um enfrentamento a epidemia de Aids em Porto Alegre. Boletim epidemiológico (Secretaria Municipal da Saúde de Porto Alegre), ano XIV, n. 48, maio de 2012, p. 1-3.

ZAMBENEDETTI, G.; BOTH, N.S. Problematizando a atenção em HIV-Aids na Estratégia Saúde da Família. Polis e Psique. Porto Alegre, v. 2, n.1, p. 99-119, 2012.

ZAMBENEDETTI, G.; SILVA, R.A.N. O paradoxo do território e os processos de estigmatização no acesso ao diagnóstico de HIV na atenção básica em saúde. Estudos de Psicologia, Natal, v. 20, n. 4, p. 229-240, 2015.

\section{Notas}

${ }^{1}$ Disponível em: <http://www.saude.rs.gov.br/wsa/portal/index.jsp?menu=servicos\&cod=2606>. Acesso em: 19 mar. 2012.

${ }^{2}$ A restituição, diferentemente da devolução, não ocorre ao final da pesquisa, sendo incorporada ao próprio processo de pesquisa (LOURAU, 1993). Trata-se de um momento onde os participantes são reunidos para uma apresentação dos dados, desencadeando movimentos de discussão e análise junto ao grupo.

${ }^{3}$ G. Zambenedetti participou das etapas de concepção, redação, análise, interpretação dos dados e revisão final do artigo. R. A. N. da Silva participou das etapas de concepção, análise e interpretação dos dados, revisão do artigo e aprovação da versão final para publicação. 


\section{Decentralization of health care to HIV-AIDS for primary care: tensions and potentialities} In this article, we seek to identify and discuss the tensions that permeate the diagnosis decentralization process for HIV and health care to people living with HIV-AIDS for primary care. A qualitative base research was conducted under the institutional analytical bias in Porto Alegre-RS, Brazil. The analysis considered data relating to crop focus groups with teams of a basic health unit, interview with the municipal coordinator of STD and AIDS policy, with matricial professional of decentralization actions in HIV-Aids and local health counselor. Issues have been identified that tension the process: incomplete teams and staff turnover; distrust of the rapid test; perception of work overload; aspects related to counseling and diagnostic communication. Among the aspects that tense positively to the realization of the process, we have identified: sensitivity to epidemiological data; working perspective on principles of SUS and family health; training and matrix support. We conclude that the process of decentralization involves a subjective mobilization of workers and their execution has better conditions to occur when the responsibility is shared instead of transferred to another place. The analysis can help managers and workers involved in similar cases.

> Key words: Primary Health Care; HIV; decentralization; comprehensive health care; institutional analysis 